\title{
25 EXPRESSION OF IL-21 RECEPTOR IN SYNOVIAL TISSUE AND BLOOD OF PATIENTS WITH RHEUMATOID ARTHRITIS
}

Marina Frleta, ${ }^{1}$ Vicky King, ${ }^{1}$ James H Reilly, ${ }^{1}$ Shauna Kerr, ${ }^{1}$ Derek S Gilchrist, ${ }^{1}$ Ditte Tornehave, ${ }^{2}$ Dorthe Lundsgaard, ${ }^{2}$ Ashley M Miller, ${ }^{1}$ lain B Mclnnes ${ }^{1}$ 'Institute of Infection, Immunity and Inflammation, GBRC, University of Glasgow, Glasgow, UK; ${ }^{2}$ Novo Nordisk A/S, Måløv, Denmark

\subsection{6/annrheumdis-2011-201238.25}

Background and objectives Cytokines regulate a broad range of inflammatory pathways in the pathogenesis of Rheumatoid Arthritis (RA), and cytokine blockade against tumour necrosis factor $\alpha$ and IL- 6 has offered substantial advances in the treatment of articular inflammation. However, a large proportion of patients will not respond or exhibit only a partial response to treatment and new therapies are thus required. IL-21 is a member of the four- $\alpha$-helix bundle family of cytokines that mediates pleiotropic effects through the IL-21 receptor (IL-21R). Since potency of IL-21 is mainly dependent on presence and abundance of its receptor on different cells types, the objective of this study was to characterise expression of IL-21R in the synovium and blood of patients with RA.

Materials and methods Immunohistochemistry for IL-21R was carried out on synovial tissue samples derived by arthroplasty from patients with RA ( $n=5)$ obtained from the Institute of Infection, Immunity and Inflammation Research Tissue Bank. Mononuclear cells were separated out from peripheral blood (PBMC) of 10 RA patients or 3 healthy controls on a density gradient using Histopaque (Sigma) and analysed by flow cytometry for IL-21R expression on T cells (CD3/CD4/CD8), B cells (CD19/CD27) and NK cells (CD16/CD56).

Results Expression of IL-21R was detected in $5 / 5$ synovial RA tissues. The IL-21R $\mathrm{R}^{+}$cells were located in the synovial intimal and sublining layers and in lymphoid aggregates. Flow cytometric analysis on blood PBMC revealed that IL-21R is highly expressed on both $\mathrm{CD}^{+}(73.04 \%, 12.58 \mathrm{MFI})$ and $\mathrm{CD}^{+}(50.88 \%, 13.69 \mathrm{MFI}) \mathrm{T}$ cells, as well as on a proportion of NK cells $(73.83 \%, 19.15 \mathrm{MFI})$ in RA patients. On B cells, IL-21R expression was higher on the CD27- fraction of naive $B$ cells $(95.19 \%$, $37.02 \mathrm{MFI})$, with lower expression on the CD27 ${ }^{+}$ memory B cells $(15.2 \%, 32.22 \mathrm{MFI})$.

Conclusions Our results show increased expression of IL-21R in established RA synovial tissue and peripheral blood, and indicate that targeting of the IL-21/IL-21R pathway may be a valid therapeutic strategy for the treatment of RA. 